\title{
Evaluation of Stress Response and Apoptosis on Leucocytes in TIVA versus Balanced Anesthesia
}

\author{
G. Soto ${ }^{1,2 *}$, F. Pignolo ${ }^{1,2}$, F. Calero ${ }^{1,2}$, F. Saucina ${ }^{1,2}$, L. Lainatti ${ }^{1,2}$, S. Molinari ${ }^{3}$, G. Harvey ${ }^{2}$ \\ ${ }^{1}$ Department of Anesthesiology, Hospital Escuela Eva Perón, Granadero Baigorria, Santa Fe, Argentina \\ ${ }^{2}$ Post Graduate Program in Anesthesiology, Faculty of Medicine, Universidad Nacional de Rosario, Santa Fe, Argentina \\ ${ }^{3}$ Biochemistry, Central Laboratory, Hospital Escuela Eva Perón Granadero Baigorria, Santa Fe, Argentina \\ Email: ^dr.germansoto@gmail.com
}

How to cite this paper: Soto, G., Pignolo, F., Calero, F., Saucina, F., Lainatti, L., Molinari, S. and Harvey, G. (2017) Evaluation of Stress Response and Apoptosis on Leucocytes in TIVA versus Balanced Anesthesia. Open Journal of Apoptosis, 6, 1-16. http://dx.doi.org/10.4236/ojapo.2017.61001

Received: November 2, 2016

Accepted: January 27, 2017

Published: January 31, 2017

Copyright (C) 2017 by authors and Scientific Research Publishing Inc. This work is licensed under the Creative Commons Attribution International License (CC BY 4.0).

http://creativecommons.org/licenses/by/4.0/

\begin{abstract}
Background: The aim of this study was to assess the stress response and apoptosis on leucocytes, in patients under two different anesthetics techniques. Methods: Thirty patients ASA I-II were prospectively randomized into two groups to receive either total intravenous anesthesia with propofolremifentanil (TIVA Group, $\boldsymbol{n}=15$ ) or balanced inhalation anesthesia with sevoflurane-remifentanil (BAL Group, $\boldsymbol{n}=15$ ). The hemodynamic response: systolic blood pressure (SBP), diastolic blood pressure (DBP) and heart rate (HR) at different time points: baseline, after intubation, after skin incision and at the end of surgery, was measured along with plasma levels of lactate, glucose, cortisol and leucocytes count. The biomarkers of apoptosis (Annexin V and Propidium Iodide) in neutrophils, monocytes and lymphocytes were evaluated at baseline, intraoperatively and two hours after surgery. Results: The study groups were comparable with respect to anthropometric data. No significant intergroup differences in SBP and DBP were revealed. The HR in the BAL group was lower after intubation $(p=0.007)$. In both groups, lactate, plasma glucose, cortisol and leucocytes count remained stable during surgery and two hours post-operatively. In the BAL group there were significant differences in Annexin V in neutrophils, baseline moment $(p=0.010)$. No significant differences were found in apoptosis markers (Annexin V and Propidium Iodide) in neutrophils, monocytes and lymphocytes, at different time points. Conclusion: Both TIVA and BAL were effective in suppressing the surgical stress, without inducing apoptosis in immune cells, in patients undergoing VCL.
\end{abstract}

\section{Keywords}

Propofol-Sevoflurane-Hemodynamics Response-Cortisol-Apoptosis in Leucocytes-Annexin V-Propidium Iodide 


\section{Introduction}

The surgical stress response reflects a combination of endocrine, immunological and hematological changes occurring after injury and trauma. Evolutionarily, the stress response is considered to be protective and supportive for survival. However, sustained stress response becomes detrimental and can contribute to the disease progression necessitating efforts to minimize extent [1]. By modulating the neurohumoral stress mediators, anesthesia may indirectly affect the inflammatory response of surgical patients, suppressing or releasing different cytokines and neurotransmitters. Additionally, anesthetics may directly affect the functions of immune-competent cells such as phagocytosis, respiratory burst, proliferation and cell count by apoptosis, after anesthetic procedures [2] [3] [4].

Apoptosis or programmed cell death is a complex process including morphological and biochemical changes mediated by a family of cysteine aspartases named caspases, which can be activated by two major apoptotic signaling pathways. In the extrinsic pathway, extracellular ligands binding to specific cells surface death receptors, cleave caspase-8 leading to apoptosis. In the intrinsic pathway, there is an increase in permeability of mitochondrial membranes that involves release of Cytochrome $C$. from mitochondria into citosol. The release of Cytochrome $C$. activates caspase-9, which consequently activates caspase-3 leading to apoptosis [5].

Anesthetics may play an important role in immunomodulation through their effects on inflammatory response and immune cells functions. It has been reported that alterations in immune system persist several days after exposure to anesthesia. Sevoflurane and isoflurane induce lymphocyte apoptosis via increased mitochondrial permeability and caspase-3 activation in vitro [6]. In contrast, propofol has antioxidant properties that can be potentially protective via modulation of apoptosis [7].

The aim of this study was to evaluate the effects of two anesthetics techniques, propofol-remifentanil and sevoflurane-remifentanil on hemodynamics, endocrine-metabolic function and immune response.

\section{Materials and Methods}

Thirty patients who underwent elective VLC were included in this clinical, prospective, and randomized trial. Approval was obtained from Ethical and Investigation Committee at Eva Perón Hospital. We only included surgeries that started at 7:30 a.m., to avoid time variations of stress hormones. All surgeries were performed using the standard four-trocar technique and pneumoperitoneum with carbon dioxide $\left(\mathrm{CO}_{2}\right)$ at an intra-abdominal pressure of between 13 and $15 \mathrm{mmHg}$. The same anesthesia team performed anesthesia in all cases.

\subsection{Inclusion Criteria}

\section{Patients ASA I}

Age ranges between 18 and 65 years old. 
Body mass index (BMI) $<35 \mathrm{~kg} / \mathrm{m}^{2}$ women; $<42 \mathrm{~kg} / \mathrm{m}^{2}$ men (limit of pharmacokinetic models).

\subsection{Exclusion Criteria}

Patient refusal.

Benzodiazepine, Opioids, Corticosteroids, $\beta$-bloquersor Calcium Channel Blockers use within 48 hours.

Hypersensitivity to Opioids or Propofol /lipid emulsion.

Chronic or Acute Inflammatory process.

Diabetes.

Autoimmune diseases.

Cancer.

After the informed consent was signed, patients were randomized to one of the following groups:

- TIVA Group: receiving propofol-remifentanil.

- BAL Group: receiving sevoflurane-remifentanil.

A medical physician blinded to the study performed a single sequence of random assignment. Using R Core Team software, R Foundation for Statistical Computing, Vienna, Austria, without imposing any restriction on randomization scheme. The investigator assessing the inclusion and exclusion criteria was blinded to the random assignment treatments.

\subsection{Anesthetic Management}

Once the patient was in the operating room, an IV cannula $18 \mathrm{G}$ with double safeguard at the three-way-stopcock for infusion of drugs, was inserted into the antecubital vein of the left arm. Fifteen minutes prior to surgery, an intravenous bolus of $0.02-0.05 \mathrm{mg} / \mathrm{kg}$ midazolam (Dormicum ${ }^{\oplus}$, Roche) was administered to patients as an anxiolytic, followed by $8 \mathrm{mg}$ Dexamethasone (Decadron ${ }^{\oplus}$ ) and 1 $\mathrm{mg} / \mathrm{kg}$ diclofenac (Dioxaflex ${ }^{\oplus}$, Bagó) forthe prevention of postoperative nausea and vomitingand preemptive analgesia. To compensate the nighttimefluid losses $10 \mathrm{~mL} / \mathrm{kg}$ saline solution was administered as a bolus followed by continuous infusion at a rate $5 \mathrm{~mL} / \mathrm{kg} / \mathrm{h}$.

\subsection{Anesthetic Procedure}

In the TIVA Group, the anesthetic induction was performed with propofol (Fresofol ${ }^{\triangleright} 1 \%$, Fresenius Kabi), Schnider pharmacokinetic model, Ce $3 \mathrm{ug} / \mathrm{mL}$, until loss of the blink reflexes. Then, a Cd $2 \mathrm{ug} / \mathrm{mL}$ was administered until the end of the surgery.

In the BAL Group, the anesthetic circuit was pre-charged with $8 \%$ sevoflurane (Sevorane ${ }^{\oplus}$, Abbott) $6 \mathrm{~L} / \mathrm{min}$ for one minute, and then the induction was performed with $8 \%$ sevoflurane using the single-breath vital capacity technique, asking the patient to take a single deep inspiration and hold the breath as long as possible during two or three times until loss of the blink reflexes. Then, anesthesia was maintained at $1.8 \%-2 \%$ end tidal concentration of sevoflurane through- 
out surgery (controlling by a monitor Infinity ${ }^{\oplus}$ Vista XL).

In both groups, following the loss of blink reflexes, anesthesia was supplemented with remifentanil (Ultiva ${ }^{\oplus}$, Glaxo) Minto model, using a loading dose $\mathrm{Cp}$ $3 \mathrm{ng} / \mathrm{mL}$, and maintenance dose $4-10 \mathrm{ng} / \mathrm{mL}$ dose was required to maintain hemodynamic stability at $20 \%$ of input parameters. To facilitate endotraqueal intubation, a $0.1 \mathrm{mg} / \mathrm{kg}$ vecuronium (Vecural ${ }^{\oplus}$, Richmond) was administered, followed by $0.02 \mathrm{mg} / \mathrm{kg}$ boluses every 40 minutes as required. Four minutes after the anesthesia was induced, the endotracheal intubation was performed and the lungs were mechanically ventilated in a volume-control mode with settings aimed at achieving mild hypocapnia (end-tidal $\mathrm{CO}_{2}$ between 30 and $35 \mathrm{mmHg}$ ), with a mixture of air and $\mathrm{O}_{2}$ at $60 \% \mathrm{FIO}_{2}$.

\subsection{Hemodynamic Parameters}

SBP, DBP, and HR were recorded using an electronic sphygmomanometer and an ECG multi-parametric monitor at the following times points: baseline, after intubation, after skin incision, and at the end of the surgery.

\subsection{Endocrine-Metabolic Parameters}

Three blood samples were taken at the following times:

- Basal: when entering the operating room;

- Intraoperatory: 30 minutes after starting the surgery;

- Two hours postoperative: two hours after extubation.

Plasma levels of lactate, glucose, cortisol, leucocytes, and markers of cell apoptosis (Annexin V, Propidium Iodide) in neutrophils, monocytes and lymphocytes were determined in every blood sample.

\subsection{Endocrine-Metabolic Biochemical Markers}

Levels of lactate, glucose and cortisol were determined with standard laboratory procedures. To measure glucose (mg\%, NV: 70 - 110) and lactate (mmol/l, NV: 0.6 - 2.2) metabolites, electrolytes, and oxymetry, a Radiometer Copenhagen Instrument, ABL 700 System blood gas analyzer was used. Cortisol (ug/dl, NV: 6.2 - 19.4) was quantified using electroche miluminescence immunoassay (ECLIA) with a Cobas e411, Roche Hitachi.

\begin{tabular}{ccc}
\hline Biochemical marker & Instrument & Normal values \\
\hline Lactate & Radiometer Copenhagen Int ABL 700 system & $70-110 \mathrm{mg} \%$ \\
Glucose & Radiometer Copenhagen Int ABL 700 system & $0.6-2.2 \mathrm{mmol} / \mathrm{l}$ \\
Cortisol & Cobas e411, Hitachi & $6.2-19.4 \mathrm{ug} / \mathrm{dl}$ \\
\hline
\end{tabular}

\subsection{Complete Blood Count (CBC) and White Blood Cell Count (WBC)}

The test was performed in peripheral blood with Sysmex Instrument XT series (XT-1800). 


\subsection{Markers of Cell Apoptosis}

Annexin V-FITC technique was used to detect apoptosis in cells. This Annexin $\mathrm{V}$ is a member of a protein family, a human recombinant protein that binds to phosphatidylserine residues exposed on the outside layer of the plasma membrane of apoptotic cells. Apoptosis markers were determined by flow cytometry using FACS-Cantoll BD, Biosciences, Software BDFACSDivaFITC, Kit Annexin V Apoptosis Detection I, 10× Annexin V Binding Buffer $50 \mathrm{~mL}$ (1 ea), FITC Annexin V $0.5 \mathrm{~mL}$ ( 1 ea) $5 \mu \mathrm{L}$, Propidium Iodide Staining Solution $2.0 \mathrm{~mL}$ ( 1 ea) $5 \mu \mathrm{L}$ ).

Propidium Iodide staining (PI) was used with Annexin V. The PI is a membrane impermeable DNA stain, which is often used to differentiate between early and late apoptosis. Briefly, $2 \mathrm{~mL}$ of whole blood was collected in EDTA and centrifuged during 10 minutes at $200 \mathrm{~g}$ to separate leukocyte-rich plasma and platelets in different tubes, trying to prevent red blood cell contamination. Then, it was centrifuged a second time at $500 \mathrm{~g}$ during 10 minutes to discard the supernatant. Cells were suspended in $1 \mathrm{~mL}$ cold PBS and centrifuged again at $500 \mathrm{~g}$ during 10 minutes discarding the supernatant. The pellet was suspended in $1 \mathrm{~mL}$ cold PBS, cells were counted and centrifuged as before. Cells were suspended in binding buffer $1 \times\left(1 \times 10^{6}\right.$ concentration $)$, and $100 \mu \mathrm{L}$ were pippeted in Falcon tube adding $5 \mu \mathrm{L}$ of Annexin $\mathrm{V}$ and $5 \mu \mathrm{L}$ of Propidium Iodide. Subsequently, it was incubated for 15 minutes in the dark, and then $400 \mu \mathrm{L}$ of Binding Buffer $1 \times$ and 100,000 events were acquired within an hour. The neutrophils, monocytes and lymphocytes were separated by FSC/SC method of light dispersion.

\subsection{Adverse Event Records}

Hypotension was defined as any SBP $<20 \%$ basal; hypertension as SBP $>20 \%$ basal; bradycardia as a $\mathrm{HR}>100 \mathrm{~min}^{-1}$ and chest stiffness as the inability to make a positive pressure ventilation. Hypotensive episodes were corrected with an increased infusion of saline and a $50 \%$ decrease of remifentanil rate, when hypotension persisted more than one minute, an intravenous bolus of $5 \mathrm{mg}$ of ephedrine was administered. When bradycardia was detected, an intravenous bolus of atropine $(0.01 \mathrm{mg} / \mathrm{kg})$ was administered. Tachycardia and hypertension were treated by increasing the rate of remifentanil ( $50 \%$ increase). When hypertension persisted more than one minute, propofol rate was increased by $50 \%$.

Intraoperative monitoring was performed by a continuous registration of ECG, body temperature, BP, oxymetry and carbon dioxide (Dragüer Infinity Vista $\mathrm{XL}^{\oplus}$, Lübeck, Germany). Volume-controlled ventilation was performedusing anesthesia workstation (Draguer Fabius Plus GS Premium ${ }^{\circledast}$, Lübeck, Germany).

Either continuous propofol-remifentanil perfusion or sevoflurane-remifentanil administration was discontinued at the end of surgery, after the last suture was placed. After surgery, the residual neuromuscular blockade was reversed with a mixture of neostigmine $(0.05 \mathrm{mg} / \mathrm{kg})$ and atropine $(0.02 \mathrm{mg} / \mathrm{kg})$ prior to extubation. Thirty minutes before the end of surgery, Tramadol $(1 \mathrm{mg} / \mathrm{kg})$ was administered for postoperative pain control. 


\subsection{Statistical Analysis}

The sample size of 30 patients was estimated to provide $85 \%$ power to detect a difference in means of 9 points in the Annexin values in neutrophils in 2 hours postoperative. We assumed a standard deviation of 7.7 units (based on previous experience). Sample size calculations were based on a hypothesis test for difference of means conducted at the 0.05 level (2-sided). Since The WilcoxonMann-Whitney test has $95 \%$ the power efficiency of the $t$ Test, the sample size required is the same as that calculated for the $t$ test, except that the power used should be divided by 0.95 that is why that power of 0.85 was used instead of 0.8 .

Continuous and categorical variables were expressed as mean \pm standard deviation (SD) and as frequency values and proportions, respectively. Continuous baseline variables were compared between groups using Student's $t$-tests after verifying the compliance with the assumption of normality by KolmogorovSmirnov (KS) test. Fisher's exact test was used to compare proportions between independent groups. Analysis of hemodynamic parameters and levels of lactate, glycemia, cortisol, and leucocytes were compared with Mann-Whitney's $U$ test at each time of assessment, since the normality assumption was not verified in both groups simultaneously even after transforming the data. Furthermore, comparisons between measurements of intraoperative and postoperative versus baseline measurements were calculated by Wilcoxon Signed-Rank test for paired samples in each group. A $p$-value $<0.05$ was considered statistically significant.

\section{Results}

The SBP, DBP, HR, lactate, glucose and cortisol levels were assessed at different time points during surgery in patients scheduled for VLC. Apoptotic response in neutrophils, monocytes and lymphocytes was studied related two anesthesia techniques.

Clinical characteristics of the patients enrolled in the study are reported in Table 1. No significant differences were observed between the groups in the qualitative and quantitative analyses. Both groups were comparable in age, weight, height, BMI, gender, and vasoactive drug requirements.

Table 1. Patients demographics. Data are expressed as: ${ }^{a}$ mean (SD)—Student's $t$-test; ${ }^{\mathrm{b}}$ no. (\%)-Fisher's exact test.

\begin{tabular}{|c|c|c|c|}
\hline & TIVA Group $(n=15)$ & BAL Group $(n=15)$ & $P$ \\
\hline Age $(\text { year })^{\mathrm{a}}$ & $38.9(16.7)$ & $37.4(13.5)$ & 0.793 \\
\hline Weight $(\mathrm{k})^{\mathrm{a}}$ & $73.4(14.4)$ & $72.8(15.4)$ & 0.913 \\
\hline Height $(\mathrm{m})^{\mathrm{a}}$ & $1.65(0.1)$ & $1.64(0.1)$ & 0.819 \\
\hline Body Mass Index ${ }^{a}$ & $26.8(3.5)$ & $26.7(4.1)$ & 0.963 \\
\hline Sex $(\text { female })^{\mathrm{a}}$ & $12(80 \%)$ & $12(80 \%)$ & 1 \\
\hline Use of efedrine $\mathrm{e}^{\mathrm{b}}$ & $2(13 \%)$ & $4(26 \%)$ & 0.651 \\
\hline Use of atropine $\mathrm{e}^{\mathrm{b}}$ & $1(7 \%)$ & $1(7 \%)$ & 1 \\
\hline Time of surgery $(\mathrm{min})^{\mathrm{a}}$ & $74.0(23.8 \%)$ & $78.3(21.6 \%)$ & 0.818 \\
\hline Time of anesthesia $(\mathrm{min})^{\mathrm{a}}$ & $88.3(26.7)$ & $95.7(25.1)$ & 0.736 \\
\hline
\end{tabular}


Hemodynamics parameters showed that both TIVA and BAL groups decrease systolic and diastolic blood pressure relative to respect baseline values after intubation (115.0 \pm 16.4 vs. $103.8 \pm 21.3)$, after skin incision (106.8 \pm 14.2 vs. 98.0 $\pm 13.2)$, end of surgery $(112.9 \pm 14.9$ vs. $112.6 \pm 13.5)$. Similar values were found respect of TAD. In the BAL Group heart rate were lower compared to TIVA Group ( $p=0.007$ ) (Figure 1).

Regarding endocrinological response, both TIVA and BAL groups showed no significant increase in lactate, glucose, and cortisol levels at the times studied compared to baseline levels. There were no differences in the white blood cell count between both anesthetic treatments nor intra and post-surgical samples compared to baseline (Table 2).

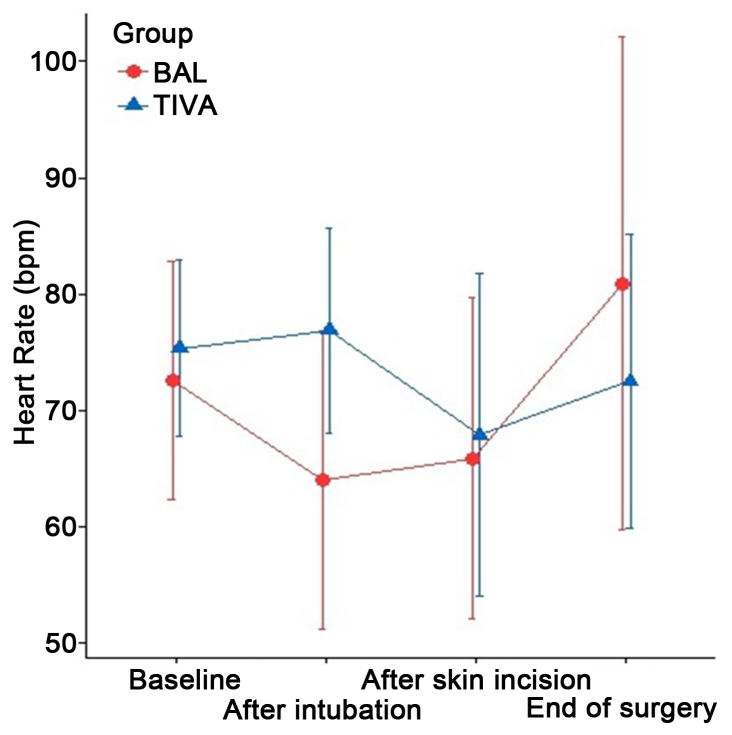

Figure 1. Hart Rate (bpm) for each group at specified perioperative periods. Points represent average and lines represent standard deviation of Hart Rate for each group at specified perioperative periods. Significant difference after intubation period between groups ( $p=0.007$; $\mathrm{U}$ of Mann-Whitney Test).

Table 2. Average (SD) of Lactate (mmol/l, Glycemia (mg\%), Cortisol (ug/dl) y Leucocytes count $\left(\times 10^{3} \mathrm{~mm}^{3}\right)$ in for each group at specified perioperative periods.

\begin{tabular}{|c|c|c|c|c|c|c|c|}
\hline \multirow{2}{*}{ Parameter } & \multirow{2}{*}{ Group } & \multicolumn{2}{|c|}{ Baseline } & \multicolumn{2}{|c|}{ Intraoperatory } & \multicolumn{2}{|c|}{$2 \mathrm{hs}$ postoperative } \\
\hline & & Average & SD & Average & SD & Average & SD \\
\hline \multirow{3}{*}{ Lactate } & TIVA & 2.18 & 1.30 & 2.02 & 1.05 & 2.44 & 0.98 \\
\hline & BAL & 1.87 & 0.59 & 1.84 & 0.54 & 2.16 & 0.75 \\
\hline & $p$ & \multicolumn{2}{|c|}{0.967} & \multicolumn{2}{|c|}{0.803} & \multicolumn{2}{|c|}{0.395} \\
\hline & TIVA & 106.20 & 32.54 & 109.07 & 30.28 & 104.40 & 26.80 \\
\hline \multirow[t]{3}{*}{ Glycemia } & BAL & 107.13 & 27.80 & 107.47 & 24.26 & 106.33 & 35.82 \\
\hline & $p$ & \multicolumn{2}{|c|}{0.950} & \multicolumn{2}{|c|}{0.917} & \multicolumn{2}{|c|}{0.693} \\
\hline & TIVA & 12.87 & 8.59 & 9.34 & 10.48 & 13.55 & 10.55 \\
\hline \multirow[t]{2}{*}{ Cortisol } & BAL & 11.85 & 7.01 & 9.33 & 6.63 & 13.30 & 6.12 \\
\hline & $P$ & \multicolumn{2}{|c|}{0.917} & \multicolumn{2}{|c|}{0.455} & \multicolumn{2}{|c|}{0.885} \\
\hline \multirow{3}{*}{$\begin{array}{l}\text { White } \\
\text { blood cell } \\
\text { count }\end{array}$} & TIVA & 6.93 & 2.01 & 7.41 & 2.99 & 7.67 & 3.14 \\
\hline & BAL & 7.04 & 2.09 & 6.85 & 2.21 & 7.05 & 1.90 \\
\hline & $p$ & \multicolumn{2}{|c|}{0.967} & \multicolumn{2}{|c|}{0.383} & \multicolumn{2}{|c|}{0.534} \\
\hline
\end{tabular}


With regard to markers of cell apoptosis, a significant difference was found in marker Annexin V in the baseline sample of neutrophils in the BAL Group ( $p=$ 0.010 ) compared with the TIVA Group (Figure 2). Neutrophils, monocytes and lymphocytes did not increase along with positive Annexin or PI during intra and post-surgical period, compared with baseline values in both groups (Figures 2-7).

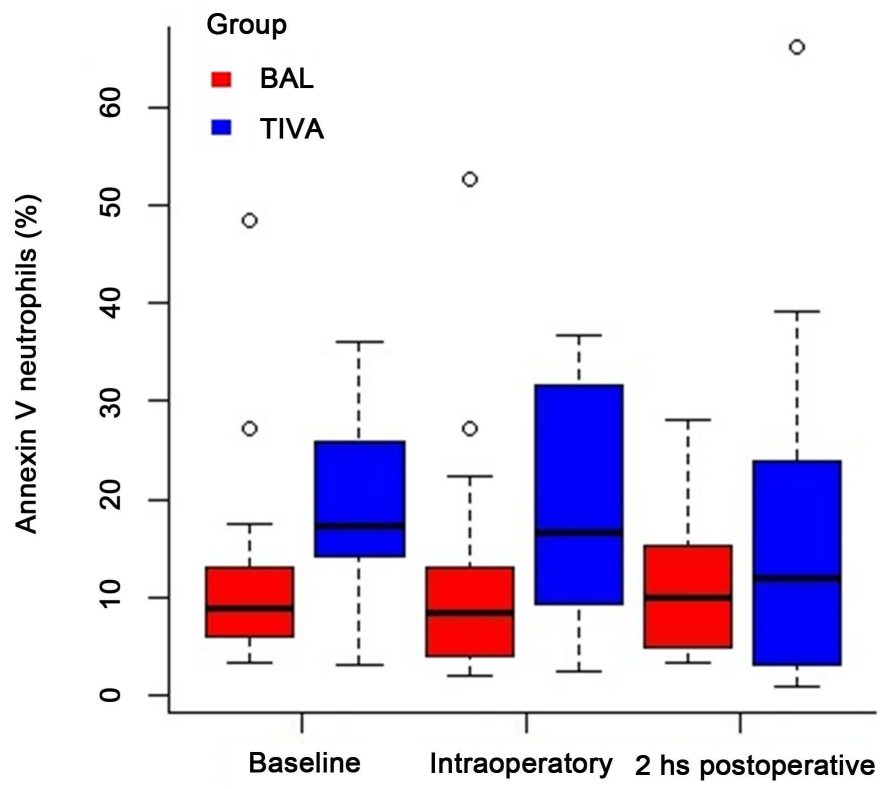

Figure 2. Distribution of Annexin values in neutrophils for each group at specified perioperative periods. Significant difference at baseline period between groups $(p=0.010$; $\mathrm{U}$ of Mann-Whitney Test).Circles stand for outliers: observations that are more than 1.5 interquartile range above quartile 3.

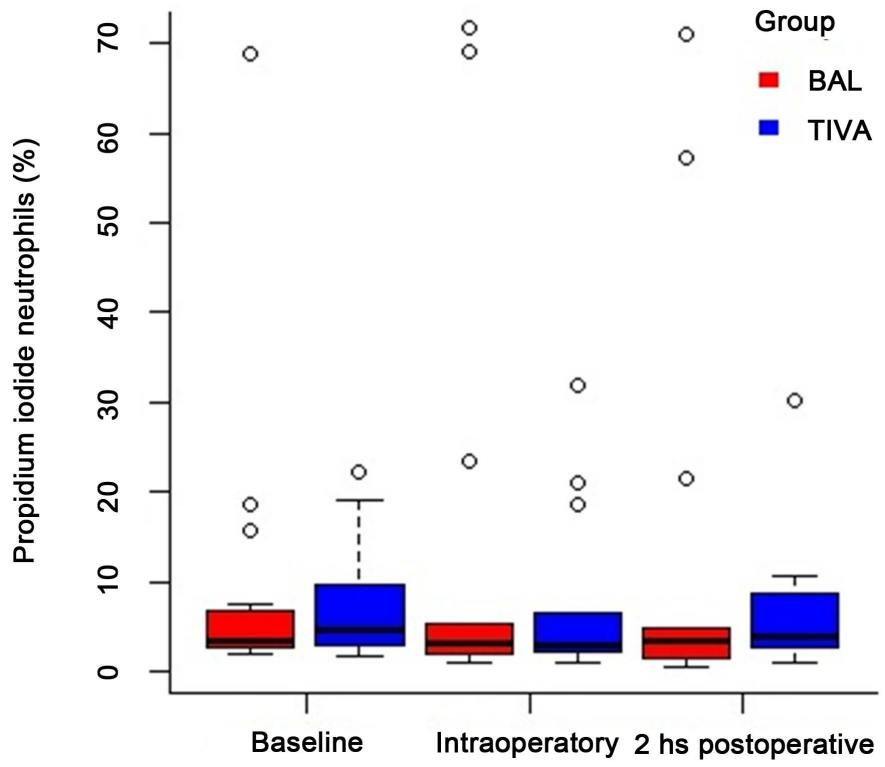

Figure 3. Distribution of Propidium Iodide values in neutrophils for each group at specified perioperative periods. Circles stand for outliers: observations that are more than 1.5 interquartile range above quartile 3 . 


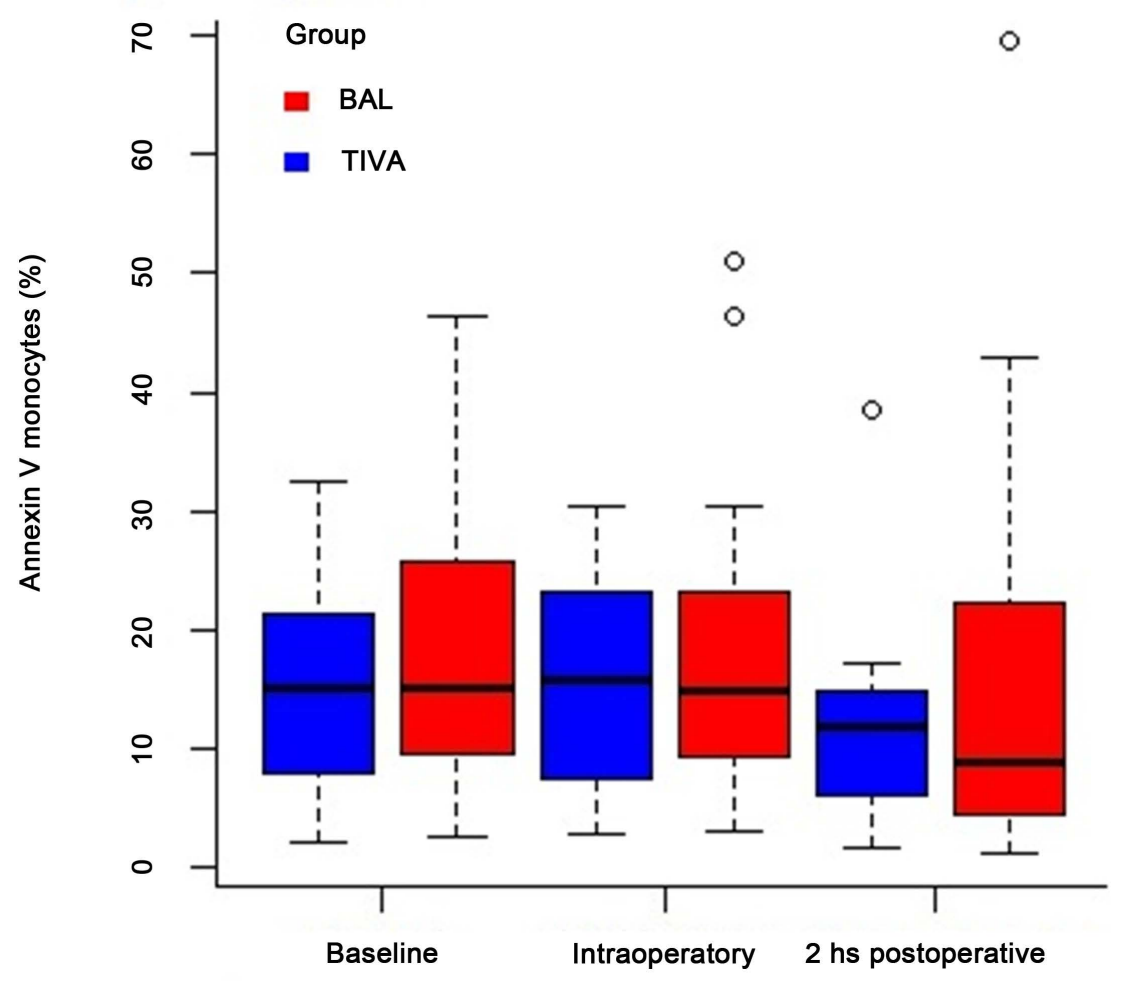

Figure 4. Distribution of Annexin values in monocytes for each group at specified perioperative periods. Circles stand for outliers: observations that are more than 1.5 interquartile range above quartile 3 .

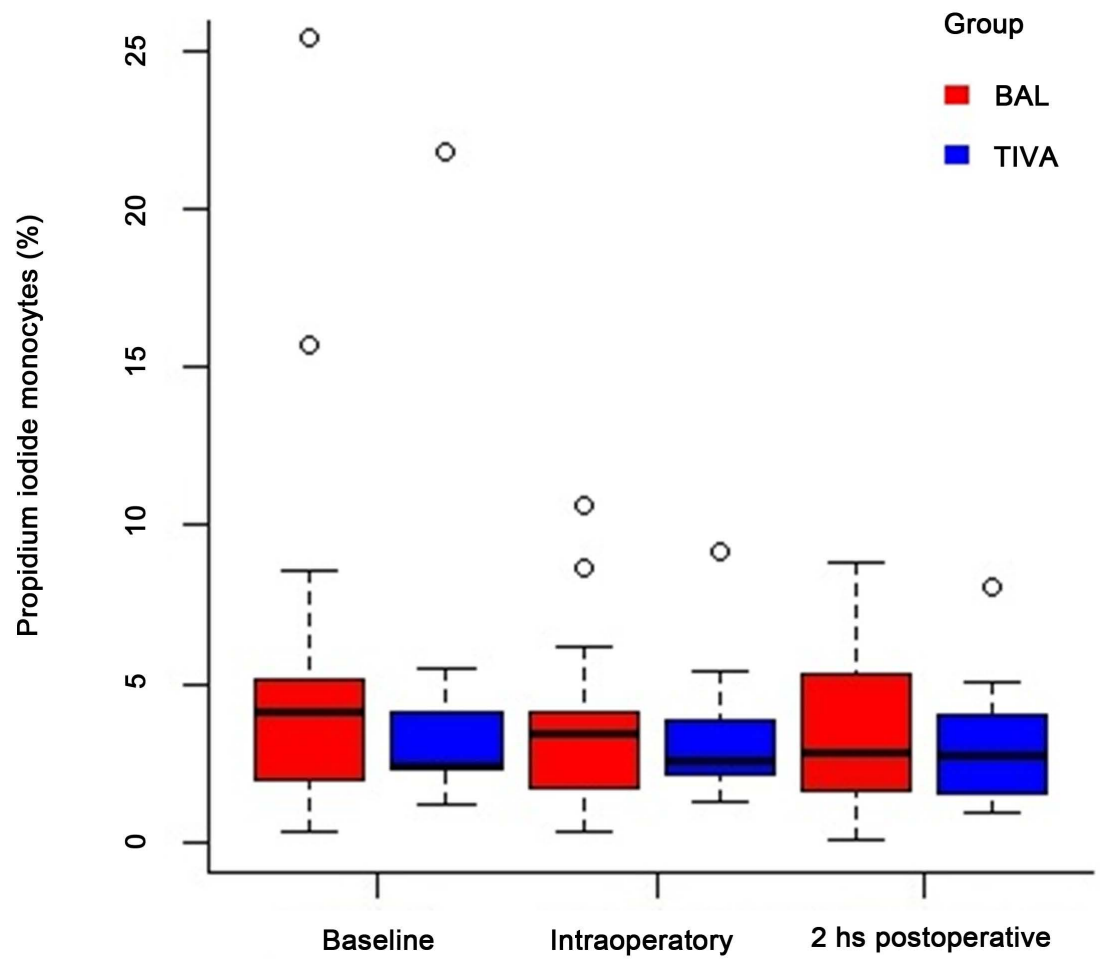

Figure 5. Distribution of Propidium Iodide values in monocytes for each group at specified perioperative periods. Circles stand for outliers: observations that are more than 1.5 interquartile range above quartile 3 . 


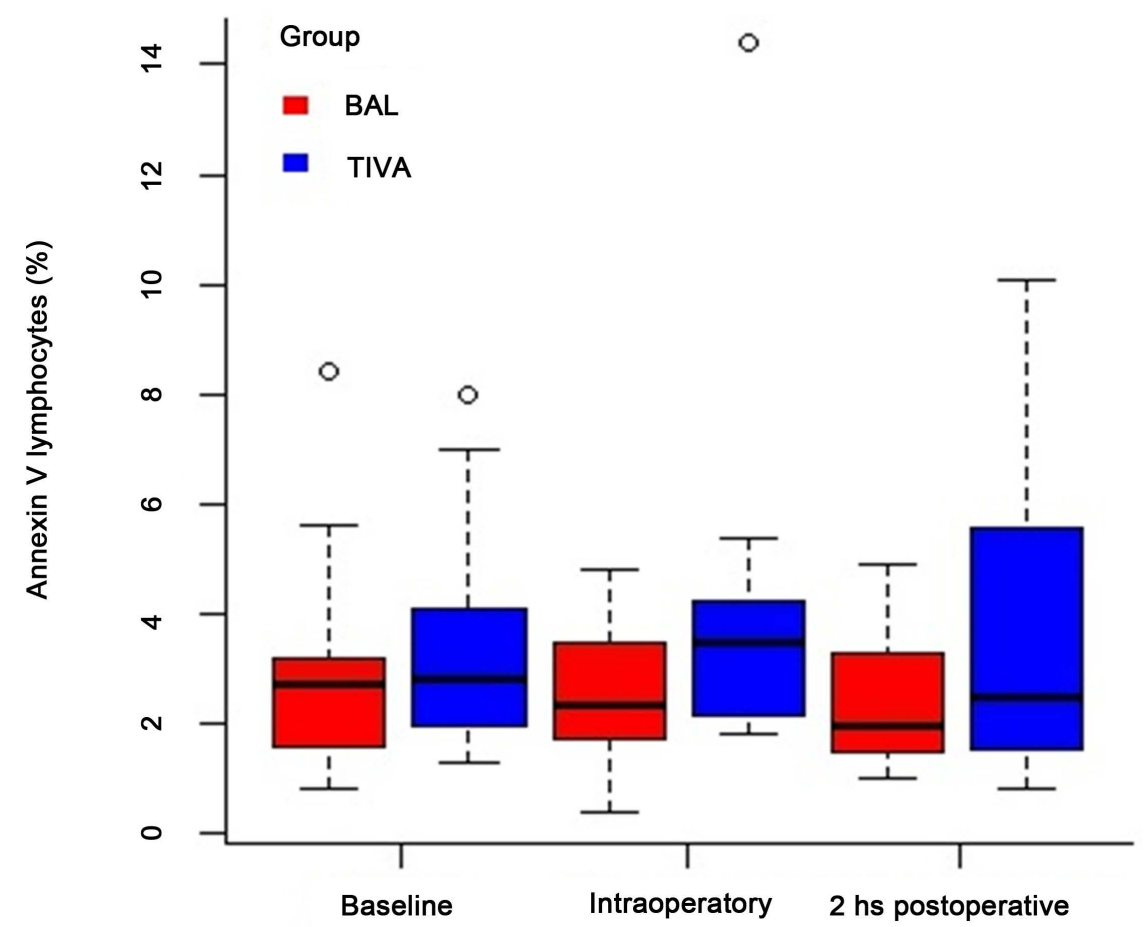

Figure 6. Distribution of Annexin V values in lymphocytes for each group at specified perioperative periods. Circles stand for outliers: observations that are more than 1.5 interquartile range above quartile 3.

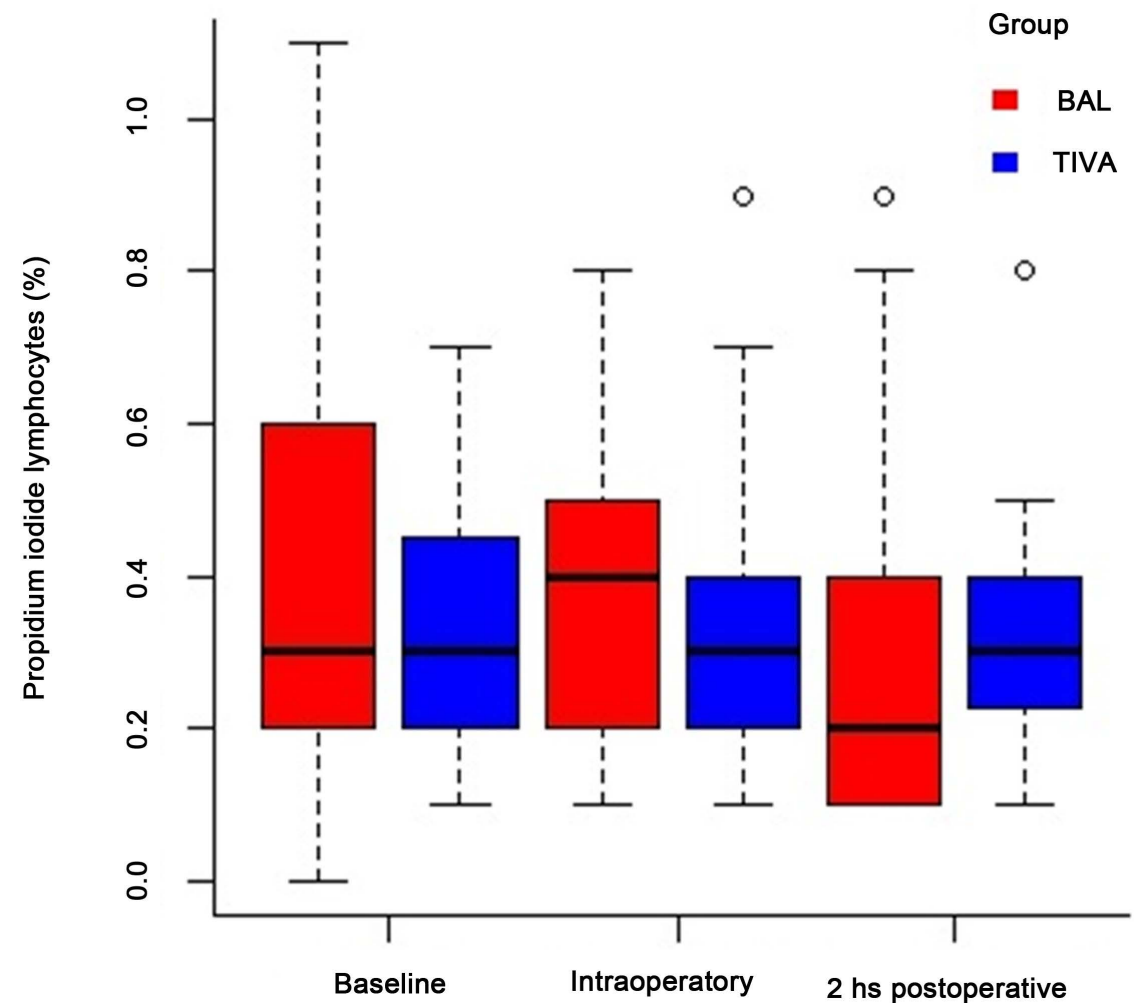

Figure 7. Distribution of Propidium Iodide values in lymphocytes for each group at specified perioperative periods. Circles stand for outliers: observations that are more than 1.5 interquartile range above quartile 3 . 


\section{Discussion}

According to hemodynamic responses, both study groups showed cardiovascular stability with decreased levels of SBP, DBP, and HR compared to preoperative values, without any difference between anesthetic techniques. At one minute after intubation, the BAL group showed a decrease in HR levels compared to the TIVA group, without any hemodynamic repercussion. Our results are in agreement with findings of a recent study by Lasinska et al., who did not observe any significant differences in hemodynamic variables between TCI propofol with 3 $\mathrm{ug} / \mathrm{mL}$ and sevoflurane $1 \mathrm{CAM}$ in patients undergoing breast surgery [8]. A similar study published in 2012 by Ahmed et al. did not report any differences in SBP and HR levels between TIVA, sevoflurane, and epidural anesthesia delivered to patients undergoing inferior abdominal surgeries [9]. The adequate control of autonomic responses could be attributable to the TCI remifentanil used in both groups. TCI systems reduce both time-dependent variability and interpatient variability, avoiding potential adverse pharmacological interaction with sevoflurane or propofol. Short-acting opioids like remifentanil administered in combination with propofol-based TIVA or volatile inhalational agents have demonstrated significant efficacies in fast-track surgeries and interventional procedures [10]. These short-acting opioids demonstrate distinct pharmacokinetics/pharmacodynamics (PK/PD) profiles that are associated with rapid onset and offset, enabling faster induction and emergence rates [11].

Regarding to endocrine response to surgical stress, the hyper secretion of cortisol and catecholamines has both anti-inflammatory and immunosuppressant effects, interfering with production of cytokines and induction of apoptosis in $\mathrm{T}$ lymphocytes. Beside, hyperglycemia exerts both pro and anti-inflammatory effects, and is considered the major predictor of adverse postsurgical outcomes. In our study, both the TIVA and BAL groups showed no significant increase in lactate, glycemia, and cortisol levels at different time points when compared to baseline levels. This suggests that both anesthetic techniques were effective in suppressing excessive activation of hypothalamic-pituitary-adrenal (HPA) axis. Unlike our results, Ihn et al. [12] detected higher level of epinephrine, norepinephrine, cortisol and glucose in the inhalation group compared to TIVA group, which reveals a better control of metabolic response using intravenous drugs. Consistent with these findings, Mujagic et al. proved that serum glucose and lactate concentrations were lower using propofol-fentanyl, compared to isoflurane-fentanyl [13]. It is possible that different volatile agents produced different metabolic response. When comparing different volatile anesthetics, isoflurane anesthesia was associated to increased cortisol levels and lymphopenia, compared to sevoflurane in surgical procedures of low stress response [14]. Interestingly, Graziola et al. [15] found a marked increase in cortisol levels during BAL anesthesia compared to TIVA, concluding that intravenous anesthesia could be a preferred technique for patients with compromised immunity. Concerning to this statement, Marana et al. demonstrated that sevoflurane improves the neuroendocrine stress response during laparoscopy compared to isoflurane [16]. 
Relating to dexamethasone, as single prophylactic dose was used for the prevention of postoperative nausea and vomiting. In patients without risk factors who received dexamethasone $20 \mathrm{mg}$ per day for five days for the control of chemotherapy-induced emesis, there was no evidence of immunosuppression or dysfunction of the hypothalamic-pituitary-adrenal axis [17].

No variation was noted in leucocytes count at different time points during surgery compared to baseline. On the other hand, Elena et al. found leukocytosis and neutrophilia in the post-operative period with intravenous and inhalational techniques [18]. Some studies suggest that inhalation agents can cause severe immune dysfunction and lymphocytopenia, but the mechanism of this phenomenon remains unclear. In addition, it has been suggested that lymphocyte disorders can occur with repeated exposures [19].

An evaluation of reactivity of apoptosis markers, in the BAL group, indicated an increased percentage of apoptotic neutrophils for the baseline samples before anesthetics exposure, without any repercussion in white cells count. Both Annexin V and PIfor neutrophils, monocytes and lymphocytes samples showed no significant differences at any time point. Therefore, this finding does not support the previous reports on cell cultures studies demonstrating apoptosis in immune cells. Loop et al. studied in vitro mechanism of apoptosis induction in T lymphocytes with sevoflurane, isoflurane and desflurane, concluded that both sevoflurane and isoflurane induce apoptosis in T lymphocytes in a dose-dependent manner [20]. It has been proposed that volatile anesthetics induce apoptosis, by altering intracellular calcium concentration via activation of inositol 1,4,5-triphosphate (IP3) receptors on the endoplasmic reticulum membrane. This activation triggers excessive calcium release, leading to an overloading in cytosol and mitochondria, which disrupts the mitochondrial membrane permeability. The subsequent release of cytochrome $\mathrm{C}$ from mitochondria enables caspase activation and apoptosis. We speculate that clinical doses of sevoflurane $1.8 \%-2 \%$ used in this study did not activate $\mathrm{IP}_{3}$ receptors in leucocytes.

The production of reactive oxygen species (ROS) is another mechanism that entails volatile anesthetics with induction of apoptosis [21]. Oxidative stress is the result of an imbalance between ROS generation and antioxidant mechanisms, causing damage to cell membranes, lipid peroxidation, protein denaturation, and strand breaks in DNA. Surgical trauma and anesthetic drugs can temporarily alter normal balance between pro-oxidants and antioxidants. Sevoflurane is biotransformed by enzyme $\mathrm{CYP}_{2} \mathrm{E}_{1}$ which also produces ROS, including superoxide anions $\left(\mathrm{O}^{2}\right)$, hydrogen peroxide $\left(\mathrm{H}_{2} \mathrm{O}_{2}\right)$, and hydroxyl radical $\left(\mathrm{OH}^{-}\right)$, which are highly reactive [22]. In this context, Wong et al. described apoptosis in neutrophils produced by exposure to sevoflurane in a dose-dependent manner, related to a ROS intracellular increase [23]. In contrast, Lee et al. stated that volatile anesthetic agents, in patients who underwent minor surgeries, did not affect neither oxidative stress nor inflammation [24]. In our study, patients underwent video laparoscopic cholecystectomy, a moderate surgical procedure in which the exposure to volatile anesthetic agents did not induce apoptosis of 
immune cells.

Propofol antioxidant profiles had been linked to its chemical structure, similar to the phenol-based scavenger, such as the endogenous to copherols. In addition, it can mitigate the effects of peroxynitrite-mediated oxidative stress and apoptosis by heme oxigenasa (OH)-1 induction, in astrocyte cellscultures [25] [26]. Allaouchiche et al. studied ROS production and glutathione peroxidase consumption in bronchoalveolar lavage fluid in swines after exposure to propofol, sevoflurane and desflurane. In the propofol group, lower levels of ROS and glutathione peroxidase consumption were observed, but no significant differences were found compared to sevoflurane group [27]. Similarly, Erbas et al. compared the effects on the oxidant/antioxidant system of sevoflurane, desflurane, and propofol infusion in patients undergoing laparoscopic cholecystectomy. According to their observation, sevoflurane and propofol significantly increased the total antioxidant capacity while desflurane increased oxidative stress [28].

Finally, induction of apoptosis by anesthetics has also been studied in neuronal tissues, with contradictory results. Several studies suggest that sevoflurane exposure induces neuroapoptosis through caspase- 3 activation and increase in $\beta$-amyloid protein levels in vivo and in vitro, while other studies suggest a neuroprotective effect [29] [30] [31]. This discrepancy could be explained by differences in cells lines, exposure time to anesthesia and concentration of inhalation agents. Recently, a dual effect of sevoflurane was suggested [32]. While short exposure times and low concentrations are linked to with neuprotection, longer exposure and higher concentrations are associated with neuroapoptosis. Future studies are necessary to test this hypothesis.

\section{Conclusion}

Both total intravenous anesthesia and balanced anesthesia were equally effective in suppressing stress response to surgery in patients undergoing laparoscopic cholecystectomy, according to hemodynamic parameters, endocrine metabolism, and cell apoptosis markers in immune cells.

\section{Acknowledgements}

The authors gratefully acknowledge Prof. Hon Dr. Gustavo Elena and Prof. Dr. Sergio Bergese for critical revision and Prof. Dr. Cristina Carrillo for her a port in oxidative stress area.

\section{Conflict of Interests}

The authors declare that there is no conflict of interests regarding the publication of this paper.

\section{Funding}

This research was supported in part by Fundación Anestesiológica de Rosario 
and the Faculty of Medicine of Universidad Nacional de Rosario.

\section{References}

[1] Scholl, R., Bekker, A. and Babu, R. (2012) Neuroendocrine and Immune Response to Surgery. The Internet Journal of Anesthesiology, 30, 3.

[2] Kelbel, I. and Weiss, M. (2001) Anesthetics and Immune Function. Current Opinion in Anesthesiology, 14, 685-691. https://doi.org/10.1097/00001503-200112000-00015

[3] Boomershine, C.S., Wo, T. and Zwilling, B.S. (2001) Neuroendocrine Regulation of Macrophage and Neutrophil Function. In: Ader, R., Felten, D.L. and Cohen, N., Eds., Psychoneuroimmunology, 3th Edition, Academic Press, San Diego, 289-300.

[4] Salo, M., Halsey, M. and Moudgil, G.C. (2001) Frontiers in Anesthesia: Allergy, Immunology and Anesthetic Action. Acta Anaesthesiologica Scandinavica, 45, 1193-1195. https://doi.org/10.1034/j.1399-6576.2001.451003.x

[5] Zhang, Y., Dong, Y., Wu, X., et al. (2010) The Mitochondrial Pathway of Anesthetic Isofluorane-Induced Apoptosis. The Journal of Biological Chemistry, 285, 40254037. https://doi.org/10.1074/jbc.M109.065664

[6] Matsuoka, H., Kurosawa, S., Horinouchi, T., Kato, M. and Hashimoto, Y. (2001) Inhalation Anesthetics Induce Apoptosis in Normal Peripheral Lymphocytes in $\mathrm{Vi}$ tro. Anesthesiology, 95, 1467-1472. https://doi.org/10.1097/00000542-200112000-00028

[7] Osman, E., Khafagy, H., Yasser, M., et al. (2012) In Vivo Effects of Different Anesthetic Agents on Apoptosis. Korean Journal of Anesthesiology, 63, 18-24. https://doi.org/10.4097/kjae.2012.63.1.18

[8] Lasinska-Kowara, M., Fardel-Reszkiewicz, E., Owczuk, R., et al. (2009) Effects of Sevoflurane versus Target-Controlled Infusions of Propofol on Hemodynamics during Elective Breast Surgery in Healthy Women. Anestezjol Intens Ter, 41, 135139.

[9] Ahmed, W. and Hamdi, N. (2012) Effects of Different Anesthetic Techniques on Inflammatory Cytokines Response and T Lymphocyte Subsets in Patients Undergoing Lower Abdominal Surgery. Ain-Shams Journal of Anaesthesiology, 5, 43-55.

[10] Mandel, J. (2014) Considerations for the Use of Short-Acting Opioids in General Anesthesia. Journal of Clinical Anesthesia, 26, S1-S7. https://doi.org/10.1016/j.jclinane.2013.11.003

[11] Soto, G., Rebora, C., Yacuzzi, M., Ciancio, M. and Harvey, G. (2013) Computer Controlled Infusion of Remifentanil: Effects, Requirements and Effect Concentrations. Revista Argentina de Anestesiología, 71, 98-115.

[12] Ihn, C.H., Joo, J.D., Kim, D.W., et al. (2009) Comparison of Stress Hormone Response, Interleukin-6 and Anesthetic Characteristics of Two Anesthetic Techniques: Volatile Induction and Maintenance of Anesthesia Using Sevoflurane versus Total Intravenous Anaesthesia Using Propofol and Remifentanil. Journal of International Medical Research, 37, 1760-1771. https://doi.org/10.1177/147323000903700612

[13] Mujagi, Z. and Čičko, E. (2007) Serum Levels of Glucose and Lactate in Patients Treated under Total Intravenous Anesthesia with Propofol-Fentanyl and under Balanced Anesthesia with Isofluorane-Fentanyl. Biochemical Medicine, 17, 71-78. https://doi.org/10.11613/BM.2007.007

[14] Omera, M. (2006) Do Volatile Inhalation Anesthetics Modify the Immune Response in Surgical Patients? Alexandria Journal of Anaesthesia and Intensive Care, 9, 34-44.

[15] Graziola, E., Elena, G., Gobbo, M., Mendez, F., Colucci, D. and Puig, N. (2005) 
Stress, Hemodynamic and Immunological Responses to Inhaled and Intravenous Anesthetic Techniques for Video-Assisted Laparoscopic Cholecystectomy. Revista Española de Anestesiología y Reanimación, 52, 208-216.

[16] Marana, E., Anetta, M., Meo, F., Parpaglioni, M., Galeone, M., Maussier, M. and Marana, R. (2003) Sevoflurane Improves the Neuroendocrine Stress Response during Laparoscopic Pelvic Surgery. Canadian Journal of Anesthesia, 50, 348-354. https://doi.org/10.1007/BF03021031

[17] Ionescu, D., Hadade, A., Mocan, T. and Margarit, S. (2014) The Influence of a Prophylactic Dose of Dexamethasone for Postoperative Nausea and Vomiting on Plasma Interleukin Concentrations after Laparoscopic Cholecystectomy. A Randomized Trial. European Journal of Anaesthesiology, 31, 204-211. https://doi.org/10.1097/EJA.0b013e3283642a01

[18] Elena, G. (2008) Evaluation of Neutrophils Function in Patients under General Anesthesia Scheduled for Laparoscopic Cholecystectomy. Revista Argentina de Anestesiología, 66, 399-417.

[19] Colucci, D.G., Puig, N. and Hernandez-Pando, R. (2013) Influence of Anaesthesic Drugs on Immune Response: From Inflammation to Immunosuppression. $O A$ Anaesthesics, 30, 3-21.

[20] Loop, T., Dovi-Akue, D., Frick, M., Roesslein, M., Egger, L., Humar, M., et al. (2005) Volatile Anesthetics Induce Caspase-Dependent, Mitochondria-Mediated Apoptosis in Human T Lymphocytes in Vitro. Anesthesiology, 102, 1147-1157. https://doi.org/10.1097/00000542-200506000-00014

[21] Yang, H., Liang, G., Hawking, B., Madesh, M., Pierwola, A. and Wei, H. (2008) Inhalational Anesthetics Induce Cell Damage by Disruption of Intracellular Calcium Homeostasis with Different Potencies. Anesthesiology, 109, 243-250. https://doi.org/10.1097/ALN.0b013e31817f5c47

[22] Bezerra, F., Bezerra, N., Oliveira, B., Augusto, A. and das Gracas, M. (2010) Evaluation of Antioxidant Parameters in Eats Treated with Sevoflurane. Revista Brasileira de Anestesiologia, 20, 93-97.

[23] Wong, C., Liu, T.Z., Chye, S.M., Lu, F.J., Liu, Y., Lin, Z. and Chen, C.H. (2006) Sevoflurane Induced Oxidative Stress and Cellular Injury in Human Peripheral Polymorphonuclear Neutrophils. Food and Chemical Toxicology, 44, 1399-1407. https://doi.org/10.1016/j.fct.2006.03.004

[24] Lee, Y.M., Song, B. and Yeum, K. (2015) Impact of Volatile Anesthetics on Oxidative Stress and Inflammation. BioMed Research International, 2015, Article ID: 242709. https://doi.org/10.1155/2015/242709

[25] Li Volti, G., Murabito, P., et al. (2006) Antioxidant Properties of Propofol: When Oxidative Stress Sleeps with Patients. EXCLI Journal, 5, 25-32.

[26] Cavalca, V., Colli, S., Veglia, F., Eligini, S., Zingaro, L., Squellerio, I., et al. (2008) Anesthetics Propofol Enhance $\gamma$-Tocopherol Levels in Patients Undergoing Cardiac Surgery. Anesthesiology, 108, 988-997. https://doi.org/10.1097/ALN.0b013e318173efb4

[27] Allaouchiche, B., Debon, R., et al. (2001) Oxidative Stress Status during Exposure to Propofol, Sevoflurano and Desfluorano. Trauma, Critical Care, 93, 981-985.

[28] Erbas, M., Demiraran, Y., et al. (2015) Comparison of Effects on the Oxidant/Antioxidant System of Sevoflurane, Desflurane and Propofol Infusion during General Anesthesia. Revista Brasileira de Anestesiologia, 65, 68-72.

https://doi.org/10.1016/j.bjan.2014.05.002

[29] Chen, G., Gong, M., Yan, M. and Zhang, X. (2013) Sevoflurane Induces Endoplas- 
mic Reticulum Stress Mediated Apoptosis in Hippocampal Neurons of Aging Rats. PLOS ONE, 8, e57870. https://doi.org/10.1371/journal.pone.0057870

[30] Zhuo, Z. (2012) Are Volatile Anesthetics Neuroprotective or Neurotoxic? Medical Gas Research, 2, 10. http://www.medicalgasresearch.com/content/2/1/10 https://doi.org/10.1186/2045-9912-2-10

[31] Yu, P., Zhang, J., Yu, S., Luo, Z., Hua, F., Yuan, L., et al. (2015) Protective Effect of Sevoflurane Post Conditioning against Cardiac Ischemia/Reperfusion Injury via Ameliorating Mitochondrial Impairment, Oxidative Stress and Rescuing Autophagy Clearance. PLoS ONE, 10, e0134666. https://doi.org/10.1371/journal.pone.0134666

[32] Dong, Y., Zhang, G., Zhang, B., Moir, R., Xia, W., Marcantonio, E., et al. (2009) The Common Anesthetic Sevoflurane Induce Apoptosis and Increases $\beta$-Amyloid Protein Levels. Archives of Neurology, 66, 620-631.

https://doi.org/10.1001/archneurol.2009.48

Submit or recommend next manuscript to SCIRP and we will provide best service for you:

Accepting pre-submission inquiries through Email, Facebook, LinkedIn, Twitter, etc. A wide selection of journals (inclusive of 9 subjects, more than 200 journals)

Providing 24-hour high-quality service

User-friendly online submission system

Fair and swift peer-review system

Efficient typesetting and proofreading procedure

Display of the result of downloads and visits, as well as the number of cited articles

Maximum dissemination of your research work

Submit your manuscript at: http://papersubmission.scirp.org/

Or contact ojapo@scirp.org 